\title{
HEIDEGGER, ROUSSEAU, NACIONALISMO Y UNIVERSALIDAD
}

\author{
Eduardo Carrasco Pirard \\ Universidad de Chile \\ educarr@manquehue.net
}

\begin{abstract}
Resumen
El artículo expone la crítica de Heidegger a la idea del pacto social de Rousseau, mostrando cómo ella conduce al pensador alemán a la afirmación de la facticidad por encima de la universalidad. Esta derivación explica por qué Heidegger cayó en el nacionalismo, y por qué simpatizó con el nazismo, alejándose con ello de los propósitos universalistas que conlleva toda filosofía.
\end{abstract}

PAlABRAS ClAVE: nacionalismo, universalidad, contrato social, facticidad, libertad, voluntad general, nazismo, Heidegger, Rousseau, Carl Schmitt.

\section{Abstract}

This article puts forward Heidegger's criticism of Rousseau's idea of the Social Contract and shows how it leads the German thinker to affirm prevalence of facticity over universalism. This drift helps to explain why Heidegger fell into nationalism and why he sympathised with Nazi politics, moving away from the universalist purposes entailed by every philosophy.

KEYWORDS: nationalism, universalism, social contract, facticity, freedom, general will, nazism, Heidegger, Rousseau, Carl Schmitt.

\footnotetext{
$\mathrm{RA}$ Si tuviéramos que buscar los fundamentos filosóficos del posicionamiento político de Heidegger en favor del nazismo, estos deberíamos encontrarlos en su crítica de la concepción política moderna, en la que curiosamente la figura de Rousseau brilla por su ausencia. Esta crítica resulta del impulso principal que guía la reflexión heideggeriana en Ser y tiempo, esto es, del intento de entregar una ontología del Ser-ahí, que, aunque parcial -en cuanto ella se centra únicamente en el propósito de preparar una respuesta a la pregunta que interroga por el sentido del ser- busca superar la noción de "sujeto", punto de partida de la filosofía de Descartes y también de la de su maestro Husserl. Atravesar la modernidad hacia un pensamiento nuevo, sería pensar al ser humano sin echar mano a la noción de "conciencia" y explicar lo social a partir de las nuevas determinaciones que surjan desde este propósito.
} 
Es cierto que la representación de Rousseau del pacto expuesta en El Contrato Social se funda en una idea del hombre entendido como individuo, noción que tiene su fundamento en el concepto de "sujeto". Los individuos son unidades sociopolíticas que, como los elementos de un todo orgánico, entran en relación a partir de sus propios intereses. El punto de partida de toda la argumentación es el "estado natural", en el que se presenta un hombre solo, siendo este hombre aislado, impedido de lograr su propia conservación por sus propios medios, el que necesariamente busca el concurso de otros hombres para poder subsistir. La sociedad se configura "por agregación de una suma de fuerzas que pueda vencer la resistencia, ponerlas en movimiento por un solo móvil y hacerlas obrar concertadamente" (Rousseau, CS, pp. 55-56). La "resistencia" a la que se hace mención aquí es la de los poderes que se oponen a la conservación del hombre en el estado de naturaleza y que terminan por imponerse frente al individuo aislado. Lo común surge de la convergencia de las voluntades individuales: "esta suma de fuerzas solo puede nacer del concurso de muchas separadas" (CS, p. 56). Así, la sociedad se explica desde la individualidad y ésta, por su parte, se concibe como lo no social. Lo social surge de lo no social, del individuo solitario. Pero no queda claro si esta generación de lo social describe un proceso que realmente haya existido de esa manera en algún momento de la prehistoria humana, o si se trata de un concepto "matemático", por decirlo así, de un modelo ideal que se presupone para explicar la situación posterior de lo social, la que, por lo demás, es la dada. O bien el pacto es un hecho que se constata, o bien es un ente de razón que el filósofo se imagina que ha ocurrido y que en tal caso explicaría la forma de lo social de un modo semejante a como se presupone el principio de inercia para explicar y calcular la trayectoria de los movimientos reales de los entes físicos. En todo caso, el modelo de explicación es, sin lugar a dudas, la física, pues desde la partida el individuo está aquí concebido como una "fuerza" y lo social, por su parte, como una "suma de fuerzas".

Esta manera típicamente moderna de pensar es lo que a Heidegger le ha parecido no dar cuenta del carácter específico de lo social, la que por ello será objeto de su crítica. Su pensamiento en Ser y tiempo va, por cierto, en una dirección opuesta, aunque en esta obra no se aborde directamente, ni el tema de lo social como tal, ni el tema de lo político. En efecto, en ella el objetivo central de análisis no es el de determinar el origen de la relación con los otros, sino el de entregar una caracterización del ser-ahí en su cotidianidad, por lo que el punto de partida es el fenómeno humano ya constituido en todos sus aspectos, tal como lo encuentra el filósofo cuando vuelve su mirada hacia él. Y cuando esto ocurre, hay que decir que algo como "lo social", o como "lo político", son fenómenos que ya están ahí. No hay ninguna forma en que la fenomenología pueda acceder al momento de la constitución de lo social, porque esta situación queda presupuesta en cualquier acto de conocimiento que se intente llevar a cabo. El conocimiento mismo presupone lo social, por lo tanto, no existe ninguna forma de acceder a una situación anterior a ello por esa vía. Por eso, cuando Heidegger hace su análisis del "ser-ahí", lo social, o su condición de posibilidad en el ser del "ser ahí" (el "ser-con"), se le aparece como una característica esencial de este ente, algo que en la descripción siempre tiene que aceptarse como dado, como habiendo estado ahí aunque antes no se hubiera reparado en ello. Y es que el "ser-con" (Mit-sein) es 
una de las tantas formas en que se especifica la diferencia ontológica entre el modo de ser del "ser-ahí" y el modo de ser de los entes "ante lo ojos" (Vorhandensein), o el de los entes "a la mano" (Zuhandensein), fenómenos en los que, debido a su exterioridad, sí es posible establecer este tipo de sucesiones. Es en estos dos últimos modos de ser donde podemos encontrar relaciones como las que describe Rousseau en su caracterización de lo social (fuerzas que se unen para formar una fuerza superior), pero no en el modo de ser del "ser-ahí", que no puede ser jamás entendido como una cosa.

La crítica a la concepción contractualista está claramente sugerida en el parágrafo 26 de Ser y tiempo, aunque no directamente abordada, cuando Heidegger, poniéndose ante la imposibilidad de pensar lo social como agregación de individuos, pregunta: “'No partirá (este modo de comprensión equivocado), entonces, de un destacar y aislar al "yo" que la fuerce a buscar luego un paso desde este sujeto aislado hasta los otros?" (SZ, p. 118). El objeto de esta pregunta es destacar su propio pensamiento del de la constitución de lo social como sumatoria de fuerzas. Este modo de partir del yo aislado, para después, a partir de él, constituir la relación con los otros, es una interpretación forzada y que pasa por encima de la experiencia auténtica de la sociabilidad. "Los otros", que son como yo soy, no son "los restantes fuera de mí, de los que se destaca el yo; los otros son, antes bien, aquellos de los cuales regularmente no se distingue uno mismo, entre los cuales es también uno" (SZ, p. 118). La separación de un yo frente a los demás es, por tanto, una abstracción que precisamente contradice la experiencia real de nuestro encuentro con los otros. En el fondo, la concepción de Rousseau, al pensar al individuo como una fuerza, está fundada en la ontología de las cosas y no en una reflexión sobre el verdadero ser del hombre. "El "ser ahí también" con ellos no tiene el carácter ontológico de un "co-ser ante los ojos" dentro de un mundo" (SZ, p. 118). El estar los hombres unos con otros conformando unidades más amplias no se debe a una agregación de unidades que termine finalmente en un conjunto, sino a una manera propia de ser del hombre, por la cual este, por su modo de ser, se encuentra siempre ya de una manera o de otra en una cierta relación con los demás.

Los otros no son nunca como cosas que estén ahí junto a otras de carácter similar, pues lisa y llanamente los hombres no son cosas y sus modos de relación deben ser comprendidos a partir de su ontología específica.

"Pero ni siquiera cuando el "ser-ahí" de los otros se vuelve temático, por decirlo así, hacen frente los otros como cosas "ante los ojos" que serían otras tantas personas, sino que tropezamos con ellos "en el trabajo", es decir, primariamente en su "ser en el mundo". Incluso cuando vemos al otro "estar por ahí meramente", no es jamás tomado como la "cosa ante los ojos" que sería un hombre, sino que el "estar por ahí" es un modo de ser existenciario; el demorarse en todo y en nada sin "curarse de", sin "ver en torno"” (SZ, p. 120).

El lazo que me une a los demás seres humanos no es explicable por una relación cualquiera a establecer a partir de la individualidad aislada, porque al ser humano simplemente no le corresponde por esencia una determinación que lo considere aisladamente. El ser humano es esencialmente social, lo social lo constituye. "El "ser con" 
determina existenciariamente al "ser-ahí, aún cuando tácticamente no sea "ante los ojos" ni percibido ningún otro" (SZ. p. 137). De ahí que Heidegger concluya que "“el ser con" y la facticidad del "ser uno con otro" no se fundan, por ende, en un "ser juntos ante los ojos" varios sujetos" (SZ, p. 120).

Por tanto, la crítica de Heidegger a la teoría del pacto social puede resumirse en los siguientes puntos:

1. Mientras para Rousseau lo social se constituye a partir de una situación natural que correspondería a la existencia del hombre aislado, para Heidegger lo social (el "ser-con") forma parte de la esencia del hombre y no es posible pensar un hombre aislado que no fuese ya un hombre, pues su propio carácter de "aislado" lo hace posible su "ser-con", su sociabilidad esencial. Para Heidegger, entonces, al revés, lo "natural" sería precisamente lo social, y lo derivado, el ser aislado, el cual no sería más que una forma determinada que adopta su ser social.

2. Este modo de sociabilidad concebida a partir del pacto es abstracta, pues para el hombre no hay ningún "antes de lo social". Lo social constituye al hombre como parte de su esencia, es algo dado, forma parte de su facticidad. Por lo tanto, si se desea pensar correctamente lo social, ello debe hacerse partiendo de la base de que, tratándose del hombre, lo social es siempre algo que ya está ahí. De donde resulta que el problema de la constitución de lo social al que responde la hipótesis del pacto, es un falso problema. No hay constitución de lo social, porque en el hombre lo social siempre está ya constituido, la constitución de lo social sería lo mismo que la constitución del hombre. Un antes de lo social es, lisa y llanamente, un antes del hombre.

Si bien hasta aquí podemos estar perfectamente de acuerdo con Heidegger, la conclusión que él saca a partir de lo dicho es lo altamente discutible. Esta conclusión tiene que ver con la acentuación no universalista de la facticidad. Esto podemos encontrarlo en diferentes textos de los años 33 y 34, como, por ejemplo, en el curso Logik als die Frage nach dem Wessen der Sprache, donde se entrega una determinación restrictiva del "nosotros" a partir de una crítica a la concepción cartesiana del sujeto. Se establece allí -siguiendo una idea que ya Nietzsche había expresado en su Zaratustra- que lo determinante en la definición del hombre es el "sí", y no el "yo", como lo piensa la filosofía moderna. Mientras en Nietzsche este concepto busca devolverle sus fueros al cuerpo en la comprensión de lo humano ("Detrás de tus pensamientos y sentimientos, hermano mío, se encuentra un poderoso soberano, un sabio desconocido -se llama 'sí mismo'. Mora en tu cuerpo, es tu cuerpo" (Nietzsche, WDB, II, p. 300)), en Heidegger la misma idea se aplicará a la facticidad y alcanzará en esta época una dimensión política: el "sí" no será otra cosa que la pertenencia de cada ser humano a su pueblo. A la pregunta por "¿quiénes 
somos nosotros?", Heidegger responde en este texto: "nosotros nos tenemos en el ser del pueblo, nuestro "ser si" es el pueblo" (LWS, p. 74). Esto quiere significar que el factor fundamental de nuestra identidad no es una conciencia pura, ni un cuerpo, sino sus arraigos, los que en síntesis pueden ser denominados "pueblo". Este modo de definir al hombre desde su pertenencia parece muy adecuado; sin embargo, esconde la trampa nacionalista en la que cayó Heidegger: "nosotros, en tanto que ser-ahí, nos insertamos a nuestra manera propia en la pertenencia al pueblo, nos tenemos en el ser del pueblo, nosotros somos ese pueblo mismo" (LWS, p. 74).

Si lo social es constitutivo del ser humano, esto quiere decir que al abrirme al descubrimiento de mí mismo, constato de inmediato que soy parte de una comunidad, que estoy en medio de otros hombres que forman ya un país, una nación, que hablan una lengua, que tienen determinadas costumbres y tradiciones, etc. Esto es cierto, pero cuando pienso estas determinaciones olvidándome de que también hay una condición básica de mi situación con los otros, que responde simplemente a mi existencia y que ya no puede describirse en términos de los lazos directos que me unen a mis conciudadanos, o a mis compatriotas, o a las unidades más pequeñas de mi pertenencia, como mi familia, mi profesión, mis aficiones, entonces se produce un desequilibrio, que es típico del nacionalismo y en el que se disuelve esa simple humanidad. Esa mera humanidad, o humanidad básica, aparece de inmediato cuando me desplazo del círculo de mis pertenencias más cercanas y entro en el terreno de otros, en el país de otros, en la familia de otros, en el lenguaje de otros. En este caso, descubro con sorpresa que eso que les pertenece a otros y que hasta ese momento no era lo mío, también puede llegar a serlo: una lengua se puede aprender, un país se puede adoptar, un paisaje se puede hacer propio, unos seres humanos que no son los que por nacimiento me han correspondido, se pueden hacer también propios. Esta experiencia de la relativización de lo propio y de la entrada en el territorio del otro es lo que le ha abierto al ser humano las puertas de la universalidad y lo que ha olvidado Heidegger durante su compromiso con el nazismo. Podemos definir el nacionalismo en esta versión heideggeriana como la afirmación del arraigo sin la universalidad, es decir, como la detención del movimiento de amplificación de los círculos de pertenencia -que normalmente deberían llegar hasta la afirmación de nuestra simple condición de seres humanos- en el pueblo propio o en los arraigos más cercanos de la sangre y la tierra (Blut und Boden).

La universalidad, por el contrario, es el descubrimiento de la condición humana, del hecho de que mas allá de lo que hasta hace un momento habíamos tomado como propio y ante lo cual parecíamos identificados sin posibilidad alguna de modificación, existe un territorio abierto y que se produce por la apertura hacia lo otro para transformarlo también en nuestro. Heidegger, por sus características personales y por desviaciones que se han producido en su ruta de pensamiento, no ha reconocido, o se ha negado a reconocer, este territorio, y ha caído entonces en la interpretación equivocada de su propia pertenencia, en la que se absolutiza la relación con el propio pueblo, sin hacer referencia a esa pertenencia más básica que es la que tengo con el resto de la humanidad y que también está incluida en el "sí mismo". A su pregunta por “¿quiénes somos nosotros?”, podríamos perfectamente responder: "simples seres humanos", habitantes de ese ámbito universal que Matta denominaba con su habitual 
profundidad: "el espacio de la especie". Así, la teoría política de Heidegger, que está fundada en una verdad descubierta por él, se ha transformado en un error negador del otro, despreciador del otro y, lo que es peor, negador de esta condición de igualdad de todos los hombres que la modernidad había comenzado a descubrir.

Pero es cierto también que el pensamiento político moderno a menudo pensó esta universalidad de manera abstracta e insuficiente. Hobbes, por ejemplo, define la igualdad de los hombres pensando principalmente en el poder que cada uno tiene de matar al prójimo, una igualdad de potenciales asesinos que queda claramente expresada al comienzo del capítulo XIII de su Leviatán:

"La naturaleza ha hecho a los hombres tan iguales en sus facultades corporales y mentales que, aunque pueda encontrarse a veces un hombre manifiestamente más fuerte de cuerpo, o más rápido de mente que otro, aún así, cuando todo se toma en cuenta en conjunto, la diferencia entre hombre y hombre no es lo bastante considerable como para que uno de ellos pueda reclamar para sí beneficio alguno que no pueda el otro pretender tanto como él. Porque en lo que toca a la fuerza corporal, aún el más débil tiene fuerza suficiente para matar al más fuerte, ya sea por maquinación secreta o por federación con otros que se encuentran en el mismo peligro que él” (Hobbes, L, p. 127).

Esta idea es la que se encuentra en la base de la decisión del pacto común, el que tiene como una de sus principales motivaciones el temor a la muerte violenta, que lleva a cada uno de los contrayentes a buscar protección en la unidad con los demás. Lo común, que moverá a los hombres hacia la constitución de la sociedad, está representado aquí por el temor, que tiene como fundamentación ontológica la noción de "poder", que preside buena parte de la argumentación del filósofo inglés. La igualdad de los hombres, lejos de ser algo puramente positivo, es la base misma de la inseguridad, pues es debido a ella que los hombres se transforman en enemigos: la igualdad es lo que dirige a los hombres hacia los mismos fines y los mueve a la competencia por su obtención. De ahí viene que si alguno obtiene para sí algún bien, su vecino necesariamente aspirará también a poseerlo, transformándose de inmediato en su enemigo. Así, en Hobbes se unen las observaciones realistas sobre lo que ha sido la historia humana, con las suposiciones de su modelo que, como en Rousseau, también está basado en una noción de estado natural en el que el hombre aparece aislado. La diferencia con el filósofo ginebrino es que aquí el estado natural aparece concebido como un estado de guerra de todos contra todos, que solo puede terminar cuando una fuerza unitaria los obligue a todos a la paz.

En Rousseau, en cambio, con mayor profundidad, se afirma que en el estado natural el hombre posee "la libertad natural y un derecho ilimitado a todo lo que lo tiente y que él pueda alcanzar" (CS, p. 61). Esto es así, porque la libertad es el punto de partida de toda su interpretación de lo social: "el hombre ha nacido libre y por todas partes está encadenado" (CS, p. 46). Todo el pensamiento político de Rousseau tiene como propósito esencial salvaguardar la libertad del hombre, pues es finalmente para mantenerse libres que los hombres se someten a la ley. La igualdad es la condición de libertad que los hombres poseen en el estado natural y que es restablecida 
en el estado social gracias a la común voluntad de someterse a la ley. Es la ley la que garantiza la libertad y la igualdad de todos, pues ella expresa los preceptos de la razón pública a través de los cuales cada individuo es consecuente consigo mismo y con sus propios designios. De este modo, no será la protección la razón principal del pacto que conduce hacia lo social, sino el interés que todo individuo tiene de expandir su propia libertad en la medida de lo posible, a través de la ley. Mientras en el Leviatán, el impulso a lo común está dado por el temor a la muerte violenta, en Rousseau será la expansión de la propia libertad, pues "la esencia del cuerpo político está en el acuerdo de la obediencia y de la libertad" (CS, p. 131). Este acuerdo está asegurado por la voluntad general, que es el fundamento de la soberanía, de modo que es al interior de la propia libertad que se encontrará el fundamento del vínculo que une a todos los hombres y los hace constituir una sociedad. Es desde las ansias de libertad que el ser humano se dirige hacia los demás, constituyéndose ésta en la base de la hermandad y la universalidad, pues solo es posible su máxima expresión en la asociación con los otros.

La universalidad de la condición humana es la esencia del hombre que tan bien ha sabido describir el propio Heidegger en Ser y tiempo, y, mejor todavía Sartre en varios de sus libros. Ella puede describirse brevemente como "la contingencia", el haber llegado a un mundo sin haberlo solicitado y en el que nos encontramos de pronto debiendo asumir nosotros mismos la tarea de existir, el que esta existencia sea, como lo afirma Heidegger, "en cada caso, mía", esto es, en el caso de alguien que tiene que hacerse cargo de ella y asumir como propio lo que ocurra con ella. La contingencia tiene que ver con que el sentido de esta venida y el mundo en el que se aterriza, sean ignotos y misteriosos, y escondan siempre sus significaciones últimas, de modo que la tarea de desentrañarlas se revela infinita. Tiene además que ver con que este mismo carácter enigmático habite siempre en todos los seres humanos en algún rincón oscuro de su alma, y también, con que la vida se nos presente como finita hasta el punto de ser una característica esencial de ella su destinación hacia la muerte, tiene que ver con que estemos todos siempre en una situación determinada por las coordenadas espacio temporales y que eso nos haga necesariamente ser de un país, de una generación, de una familia, de un lenguaje, de una cultura, de una historia. Todas estas características son esenciales y comunes a todos los seres humanos y conforman esta situación definitoria de nuestra condición. Seamos lo que seamos en lo concreto y determinado de nuestras vidas, ellas son la base y el fundamento de toda nuestra existencia y por eso mismo nos hermanan con todos los demás hombres. Cuando por cualquier desviación esta perspectiva universalista se pierde, se cae de inmediato en el desconocimiento del otro, que puede conducir, como ocurrió en Alemania, al avasallamiento del otro y al quiebre de los lazos que irremisiblemente unen a los hombres en una humanidad. Heidegger, como muchos otros alemanes aquejados por la precaria situación histórica de su país en la postguerra, sintió la necesidad de afirmar con fuerza sus valores 
nacionales, pero lamentablemente en este juego cayó en el exceso antihumanista. Por cierto que no debe confundirse su crítica posterior a la modernidad y al humanismo (antropocentrismo), con estas desviaciones ocurridas a comienzos de los años 30. Por lo tanto, podemos concluir que la crítica de Heidegger a Rousseau, en cuanto a que en él no se le haría justicia a la naturaleza esencial del hombre debido a sus limitaciones ontológicas que sirven de fundamento a la teoría del pacto, es correcta, sin que por ello tengamos que admitir también algunas de sus conclusiones políticas posteriores que anulan la universalidad.

El principio de igualdad se podría expresar de la siguiente manera: "la vida de cualquier hombre podría ser la mía". Que la que tengo sea efectivamente la mía, eso es una casualidad, un azar, pero también una necesidad, puesto que de hecho es la mía y no está dentro de mis posibilidades cambiarla. El no poder cambiarla, sin embargo, no es un destino que me libere del azar, sino que es precisamente el factor que me empuja de lleno en él. No soy ni una necesidad que me pudiera salvar del azar, ni un azar que me pudiera salvar de la necesidad. Por lo tanto, mi vida es una necesidad y, al mismo tiempo, un azar. Y eso es justamente lo que me obliga a ver al otro como igual a mí. Soy yo mismo definitivamente, pero podría haber sido otro. En todo momento, los cambios que experimento me están mostrando que mi vida es siempre otra: yo no era casado, otros lo eran, y ahora yo también lo soy. Yo no era rico, otros lo eran, y ahora yo también lo soy. Yo no era viejo, otros lo eran, y ahora yo también lo soy. Cada momento de mi vida es una confirmación de mi particularidad y, a la vez, de esa relatividad que me conduce a la universalidad: soy quién soy, podría ser como ahora es otro y, necesariamente, más adelante seré otro.

Solo la mala fe puede esconder este hecho; ella afirma: "yo soy el que soy y siempre seré el mismo, nunca seré como el otro". De ahí que todas las experiencias de transformación sean conducentes al universalismo, a la relativización de mis particularidades del momento anterior, pero sobre todo, la experiencia del exilio, en la cual es mi pertenencia más básica la que queda relativizada. Así como la vejez mira a la juventud con condescendencia porque sabe que más adelante todo eso que parecía definitivo, con el tiempo se perderá, así también el exiliado mira con condescendencia a aquellos que viven la pertenencia a la patria como un arraigo absoluto: él sabe que lo que el otro cree definitivo e inmodificable es algo que perfectamente puede cambiar y que cambiaría si él fuera forzado a abandonar su país. El exilio es una escuela de universalidad y así fue comprendido por Nietzsche cuando veía en los judíos la fuerza que transformaría Europa, terminando con las ataduras nacionalistas que se le aparecían como el gran límite que la cultura europea debía salvar. Aunque con una valoración opuesta, también así lo vieron los nacional socialistas, que pensaban que los judíos eran un obstáculo para llevar a cabo sus planes de exclusividad nacionalista y así también lo vio probablemente Heidegger, que fue capaz de hablar del "judaísmo" en el sentido que se quiera, pero de cualquier manera implicando una cuota de afirmación de lo propio, excluyente y sectaria. Él pensó estar superando al contractualismo, al descubrir la importancia del arraigo desde su noción de facticidad, pero al cerrarse a su espíritu universalista no fue capaz de aquilatar su grandeza, ni de ver hasta qué 
punto esta dirección de pensamiento, frente a la ceguera nacionalista, todavía tendría un destino por cumplir.

La idea de Rousseau busca hacer coincidir la libertad individual con la pertenencia a una sociedad. Su objetivo es "encontrar una forma de asociación que defienda y proteja con toda la fuerza común, la persona y los bienes de cada asociado, pero de modo tal que cada uno de éstos, en unión con todos, solo se obedezca a si mismo, y quede tan libre como antes" (CS, p. 56). Tal como él mismo lo afirma: "este es el problema fundamental, cuya solución se encuentra en el contrato social" (CS, p. 56). Ahora bien, es esta forma de surgimiento de lo social a partir de lo individual y explicado desde un interés, lo que a Heidegger le parece peligroso, pues ello determina desde un comienzo un movimiento de desagregación de la sociedad. La oposición de intereses entre los diferentes individuos, o entre los grupos de individuos existentes al interior de una sociedad organizada de este modo, conlleva la imposibilidad de reagrupar al conjunto de los ciudadanos en una sola dirección que el Estado represente. La democracia representativa y los sistemas parlamentarios fundados en estas ideas tendrían como necesaria consecuencia las oposiciones múltiples, las que por no haber ninguna instancia que constituyera y dirigiera al todo en una sola dirección, parecerían llevar finalmente hacia una paulatina división de la sociedad. De allí entonces la necesidad de arraigarse en lo nacional, que de acuerdo con Heidegger aparece como la única instancia capaz de devolver a la comunidad el hombre abstracto de la modernidad. Por eso, él hace una diferencia entre lo que sería una "sociedad" (Gesellschaft), es decir, una agrupación de individuos que se unen por intereses comunes en una totalidad surgida por convención, y una comunidad (Gemeinschaft), que, por el contrario, correspondería a la figura de un pueblo que reconoce un origen y un destino comunes. Las ideas de Rousseau entenderían equivocadamente la comunidad como una sociedad, porque pensarían al ser humano desde una subjetividad sin facticidad, sin arraigo. Para corregir esta insuficiencia, una nueva idea de comunidad habría surgido en Alemania como resultado de la Primera Guerra Mundial, idea que Heidegger entiende como la expansión al conjunto de la sociedad, de la camaradería surgida entre los soldados en el frente de batalla, y que se habría constituido en la base de la relación de obediencia y conducción proclamada por el nacionalsocialismo: "El nuevo espíritu de la comunidad en cuanto que camaradería, tiene en sí mismo como ensamblaje portador, la relación vital de seguimiento y conducción" (Heidegger, RL, p. 300). Esto justificaría la instauración de un Führer, que represente al Estado alemán y que dicte las líneas políticas a seguir por el resto del pueblo.

La verdad es que todos estos temas ya venían siendo tratados desde los comienzos de la postguerra por el filósofo político Carl Schmitt, quien, junto a Heidegger, y el mismo día (1 de mayo de 1933), también terminará estampando su firma en las listas de militantes del nacionalsocialismo. En sus pronunciamientos políticos, Heidegger 
se ve directamente influenciado por Schmitt en sus tesis "decisionistas", que son tan críticas de la democracia como las del pensador de Friburgo. El "decisionismo" es una filosofía política que también pretende contraponerse a la racionalidad iluminista, interpretada como fuente de la disgregación, en cuanto despierta el espíritu crítico y transforma todo problema en una interminable deliberación sobre su validez. Frente a estos excesos del espíritu crítico, que según esta opinión conducirían a la inacción, se pretende afirmar en los asuntos políticos el carácter fundamental de la decisión y de la voluntad. Toda acción política nacería de una decisión que no necesariamente se atendría -o debería atenerse- a criterios de carácter racional, moral o estético. El liberalismo, que establece la discusión como un valor fundamental de la democracia, sería un peligro para la nación, en la medida en que rápidamente se transformaría en un factor corrosivo, al ubicar los intereses del individuo y sus opiniones como la instancia suprema de la vida social. Como en Heidegger, aquí el criterio esencial estaría dado por la lucha en contra de la disgregación social, que, si tomásemos como único punto de referencia acerca de ella la desastrosa experiencia de la República de Weimar, tendríamos que concluir que efectivamente puede ser el camino más directo para llegar al abismo. Este es el tema que ha obsesionado a estos pensadores y por eso ambos vieron con buenos ojos el advenimiento del gobierno autoritario de Hitler.

Pero se podría afirmar que las críticas de Heidegger y de Schmitt a la democracia de "estilo francés" no tienen en cuenta algo esencial y es que Rousseau ha buscado establecer lo común a partir del pacto y darle además un contenido ético, más que político. Su idea es que el pacto genera inmediatamente una voluntad común, la "voluntad general", que por haber surgido desde el interés de todos tiende necesariamente hacia la utilidad pública. Pero esta voluntad general es un término de referencia que se distingue de la simple voluntad de todos, expresada, por ejemplo, en una votación. "Hay mucha diferencia entre la voluntad de todos y la voluntad general" afirma Rousseau. Mientras la voluntad general tiene siempre esta connotación ética que se ubica por encima de cualquier interés particular, la voluntad de todos no es más que la suma de las voluntades particulares. Nuevamente encontramos aquí operando el principio rector de esta filosofía, que busca constantemente reenviarnos hacia la idea, la que por sobrevolar los hechos prácticos, a la vez los explica y les da un sentido. De ahí que la confrontación de intereses dentro de la sociedad no termina necesariamente con la disolución de lo común, como lo ven Heidegger y Schmitt. A pesar de todas las desavenencias que puedan producirse en una sociedad, no por ello desaparece la voluntad general, ni pierde ésta la vigencia de su contenido ético regulador. Mientras Schmitt, para resolver el problema de la disolución de lo social por causa de los conflictos entre las partes, propone directamente un gobierno dictatorial, Rousseau ve en la dictadura misma, incluso si esta es surgida de un régimen en el que se imponen las mayorías (que es el caso que se ha producido en Alemania con el surgimiento del nacionalsocialismo) la causa principal de la desagregación de la sociedad: “...cuando una de estas asociaciones es tan grande que supera a todas las demás, ya no tenemos por resultado una suma de pequeñas diferencias, sino una diferencia única. Ya no hay entonces voluntad general y el parecer que prevalece no es ya más que un parecer particular" (CS, p. 69). 
Por lo tanto, la voluntad general es un concepto rector, regulador, no una realidad equivalente a la suma mayoritaria de las voluntades particulares y lo que busca rescatar es precisamente la dimensión comunitaria que echan de menos sus críticos. Como lo afirma Rousseau, ella es "siempre recta y siempre se dirige a la utilidad pública", lo cual quiere decir que rara vez tiene una expresión pura en la realidad política. Se trata de un concepto límite, es decir, de un a priori político que hay que postular porque toda sociedad democrática parece suponerlo. La voluntad general se constituye como esa voluntad que todos los individuos de una sociedad deberían tener si no fuesen ellos parte a su vez de agrupaciones con intereses que de alguna manera se oponen al interés general. Por eso, si se pudiera hacer abstracción de las diferencias, lo que se expresaría necesariamente sería justamente esa voluntad general. De ahí la conclusión de Rousseau, "Conviene pues, para obtener la expresión de la voluntad general, que no haya ninguna sociedad parcial en el Estado y que cada ciudadano opine según él solo piensa." (CS, p. 69). De este modo, al pensar cada individuo coherentemente desde su interés como ser humano que busca expandir al máximo su libertad, no hay ningún obstáculo para que la suma de todas las voluntades dé como resultado la voluntad general. La democracia no es la trifulca formada por el choque de intereses diversos, como piensan Heidegger y Schmitt, sino el régimen en que necesariamente se busca imponer la voluntad general, que por lo demás, también expresa, y necesariamente por implicar una racionalidad, la voluntad de todos los hombres.

Curiosamente, es este mismo ideal de unidad entre los individuos y el Estado que marca la dirección fundamental del pensamiento político de Rousseau, lo que postula Heidegger equivocadamente como una particularidad de la experiencia política alemana. Sus ideas nacen de un diagnóstico equivocado sobre la historia alemana: a comienzos del siglo XIX, el país, disgregado en pequeños estados, se habría visto sometido por Napoleón y sus aliados. A pesar de esta situación extrema, se habría hecho presente ya en ese momento "una Alemania secreta", en la que se escondía un nuevo concepto de libertad. "Desde el apremio más interno y bajo el yugo de la servidumbre externa surgía una nueva libertad. Esto quiere decir que: la esencia de la libertad fue concebida de nuevo e implantada en el saber y en la voluntad de los alemanes (CS, p. 291). Según esta interpretación, contrariamente a todo lo que nos presentan los documentos de la época sobre los debates ideológicos que tuvieron lugar en el país desde 1789, y de los cuales nos dan testimonio las biografías de Kant, de Hölderlin, de Schelling, Hegel, Fichte -por nombrar unos pocos-, los alemanes se habrían mantenido incólumes frente a las influencias de las ideas de la Revolución Francesa, y como el prestidigitador que saca el conejo de su sombrero, habrían sido capaces de crear una idea de libertad social completamente original. "Libertad quiere decir: ligazón con la ley del todo", tal sería el descubrimiento de los alemanes, según Heidegger, lo cual, aplicado a las relaciones entre el ciudadano y el Estado, vendría 
a significar la completa identificación de la voluntad del primero con la del segundo. Solo que Rousseau hablando de la transición desde el estado natural al estado civil ya había escrito prácticamente lo mismo: "Podríase añadir a lo que precede, la adquisición de la libertad moral, que por sí sola hace al hombre dueño de sí mismo, ya que el impulso del apetito constituye la esclavitud, en tanto que la obediencia a la ley es la libertad" (CS, p. 61).

Estas ideas de Heidegger, una vez despojadas de sus connotaciones nacionalsocialistas (la idea de "Volk", por ejemplo), no hacen otra cosa que explicitar la intención integradora existente en el concepto de "voluntad general". La diferencia está en que mientras para Rousseau este vínculo encierra una relatividad y, por consiguiente, queda abierto, tanto hacia la constitución de unidades más amplias, como hacia otras más pequeñas, en el caso de Heidegger la unidad es cerrada y se constituye a partir del arraigo en un determinado pueblo, que habría seguido un camino diferente al del resto de los países occidentales contaminados con el liberalismo. Pero en Rousseau, la voluntad general puede ser tanto la expresión de una parte dentro del todo, como también de todos más amplios en los cuales la sociedad de que se trataría sería una parte. "Pero cuando se forman facciones y asociaciones parciales a expensas de la grande, la voluntad de cada asociación se hace general respecto de sus miembros y particular respecto del Estado" (CS, p. 69). Por eso, también podría extrapolarse esta idea y afirmarse que así como existe una voluntad general de una nación determinada, también podría existir una voluntad general de un grupo de naciones, e incluso una voluntad general que corresponda al todo de la humanidad. De ahí que el pensamiento de Rousseau sea factible de ser aplicado a un contexto de universalidad, a una comunidad política fundada en el acuerdo de sujetos autónomos y racionales en condiciones de libertad, igualdad y reciprocidad, respecto de su interés común. Esto, como se puede ver, es lo que ha permitido que sus ideas políticas mantengan una especial vigencia en la era de la expansión democrática a nivel planetario.

En el caso de Heidegger, lo que se nos presenta es de un extremo localismo, pues lo que él afirma de la libertad y de la voluntad del Estado es solo válido para el caso de su país: serían los alemanes los que tendrían esta particularidad histórica, nacida de la experiencia política prusiana donde se habría constituido un sistema político fundado en lo popular o lo comunitario. Por eso, la frase que inicia el texto que comentamos es "Libertad tendrá para los alemanes, ahora, un sonido y un sentido nuevos". Este sonido y este sentido nuevo es el que para Heidegger resonaba ya en las marchas de las huestes nacionalsocialistas. Lamentablemente, como se pudo constatar, muy poco tenía que ver con la verdadera libertad. Porque, ¿qué sentido tendría un pensamiento con esta validez tan limitada? El pensamiento es necesariamente universal y tal como lo hemos mostrado en otro trabajo (Carrasco 2007) coincide a la vez con lo común. "Pensar, es pensar lo común a todos" (Heráclito. Frag. 113) y "Mientras el Logos verdadero es universal, el mayor número vive tomando el pensamiento como una cosa particular" (Heráclito. Frag. 2). La filosofía es, a la vez, el camino hacia lo común y la apertura hacia lo universal, de donde, como lo afirmará el propio Heidegger cuando en su pensamiento la filosofía vuelva por sus fueros, ninguna filosofía puede ser nacionalista. 
El enfrentamiento entre este Heidegger afín al nacionalsocialismo y Rousseau, nos permite mostrar de qué modo el filósofo alemán, movido por un propósito legítimo de superar la modernidad, avanza en un respecto, mientras retrocede en otro. A partir de este doble resultado, podemos sentar un principio importante: la modernidad solo es superable en la medida en que seamos capaces de asumir adecuadamente su herencia, lo que nos obliga a repensar el verdadero alcance de los pensamientos que en ella han nacido. La crítica de las insuficiencias ontológicas no es suficiente para descartar el pensamiento político moderno en bloque, como lo hace Heidegger, y menos todavía si se presume que Alemania se habría mantenido libre de sus influencias. Donde la confusión llega al límite es cuando se afirma que el nacionalsocialismo sería la expresión auténtica de esta línea política puramente germánica. Es importante entonces analizar brevemente donde puede estar la trampa que indujo a Heidegger a caer en este error y que, como vemos, tiene que ver con la suplantación de la filosofía por una opción política.

Si lo que afirma Heidegger en Ser y tiempo sobre la destrucción de la historia de la ontología es verdad, tendremos que convenir en que el filósofo debería desconfiar de todo horizonte de acción particular en el que no exista todavía una fundamentación pensante. Allí donde no hay aún un esfuerzo riguroso de pensamiento que permita afirmaciones verdaderamente sólidas, por estar basadas en una destrucción de los prejuicios que operan necesariamente en el mundo de la opinión común, el filósofo tiene que tomar distancia, pues de otro modo corre el riesgo de avalar afirmaciones apresuradas y de ceder ante la doxa, que es precisamente el ámbito de donde él debería querer salir. Y la política, en cuanto actividad que tiene lugar precisamente en este territorio, es lo que mejor podría ilustrar estos peligros, pues ella se mueve justamente en el paisaje de lo particular, y de lo público y masivo. La política, en cuanto acción que es sostenida por movimientos masivos, actúa siempre en el terreno de la apariencia y es precisamente una de las instancias más poderosas de este reino, de ahí su necesaria vinculación con la publicidad. Por lo tanto, entrar en el terreno de la política es necesariamente entrar en el suelo de lo no filosófico, de los partidismos, de lo apariencial, donde domina el "uno" (Das Man), donde se especula sobre la base de las habladurías y donde nada es tal como se dice que es, o tal como aparece que es. Nietzsche es sin lugar a dudas quien mejor describió en su Zaratustra estas relaciones: "Donde cesa la soledad, allí comienza el mercado y donde comienza el mercado, alli comienza también el ruido de los grandes comediantes y el zumbido de las moscas venenosas" (WDB, II, p. 316). La filosofía no tiene nada que ver con el mercado y si Heidegger entró en este juego de la política lo hizo traicionando su vocación de filósofo. Sus razonamientos nacionalistas son disquisiciones políticas, sin ningún valor en el ámbito de la filosofía.

Según las explicaciones que él mismo ha entregado, su incursión en la política se debería a la convicción de que el movimiento nazi representaba una respuesta al 
problema del nihilismo y de la técnica. Estos problemas se planteaban paralelamente en dos planos: al interior de la democracia alemana como una tendencia hacia la desagregación (Parlamento dividido en 32 partidos y confusión general de opiniones y tendencias), y en la universidad, como una destrucción del principio de unidad del saber. Las ciencias, empujadas por el proceso técnico hacia una cada vez mayor especialización, han tendido a desgajarse del núcleo central que las unía en una universidad, perdiéndose con ello el rol propio de la filosofía, que es la única disciplina que podría aspirar a otorgar esta unidad. Con este proceso, es la esencia misma de la universidad la que se encontraba en peligro y el designio de política universitaria heideggeriano consistía en mostrar en la nueva situación de las ciencias de qué manera la filosofía podía cumplir este rol unitario.

Lo "positivo" del nazismo en el orden político social era que al basar la coherencia de la nación en el pueblo (Volk), este movimiento respondía a la tendencia al desarraigo que conlleva el nihilismo y la técnica, y que Heidegger en toda su trayectoria de pensamiento ha visto como un fenómeno altamente peligroso. Él pensó que podía aprovechar esta idea que a él le parecía ir en el sentido correcto y encauzarla también hacia una recuperación de la universidad, sobre la base de una asunción radical del inicio griego. De este modo, el movimiento político, que tanto éxito tenía en ese momento en Alemania, podría servir también para que la universidad volviera a adentrarse en su propia esencia. Así, el nihilismo desagregador, cuyas consecuencias negativas se veían tanto en la sociedad, como en la universidad, parecía encontrar una respuesta adecuada en el nazismo, en la medida en que este se apartara de sus pronunciamientos más peligrosos, como el exagerado antisemitismo o la demagogia verbal de sus dirigentes.

Una excelente exposición de cómo pudo verse el nazismo como una respuesta al nihilismo nos la entrega Jonathan Littel en su reciente novela "les Bienveillantes" (LB, p. 544). Explicando cuál podría ser la legitimidad de este movimiento, el protagonista de la obra describe este proceso:

"Todo hombre desea satisfacer sus necesidades y permanece indiferente frente a las de los demás. Y para que los hombres puedan vivir juntos, para evitar el estado hobbesiano del "Todos contra todos" y, al contrario, para -gracias a la mutua colaboración y al aumento de la producción que de ella deriva- satisfacer una suma mayor de sus deseos, es preciso instancias reguladoras, que le tracen límites a esos deseos y arbitren los conflictos: ese mecanismo es la Ley. Pero es preciso aún que los hombres, egoístas y débiles, acepten la obligación de la Ley y así esta debe referirse a una instancia exterior al hombre, debe ser fundada sobre una potencia que el hombre experimente como superior a él mismo. Como yo le había sugerido a Eichmann durante nuestra cena, esta referencia suprema e imaginaria ha sido largo tiempo la idea de Dios; de ese Dios invisible y todopoderoso ella se ha deslizado hacia la persona física del rey, soberano de derecho divino; y cuando ese rey perdió la cabeza, la soberanía ha pasado al pueblo o a la nación y se ha fundado en un "contrato" ficticio, sin fundamento histórico o biológico, y, por tanto, tan abstracto como la idea de Dios. El nacionalsocialismo ha querido anclarlo en el Volk, una realidad histórica: el Volk es soberano y el Führer expresa, representa o encarna esta soberanía". 
Así, el nazismo sería una posibilidad de reconstruir la unidad de la nación sobre una base nueva (el Volk) y, a la vez, una oportunidad de reconstruir la unidad del saber sobre bases que además no serían tan alejadas de los fundamentos políticos, pues del mismo modo como se recupera la nación abandonando las falsas ilusiones de una democracia, también se podría recuperar la universidad volviendo a recuperar la fuerza original del saber en el inicio griego. En ambos casos, se trata de una vuelta al origen: en la política, el Volk significa un intento de asentar la sociedad sobre las bases de las fuerzas del arraigo, y en el saber, se trata de una vuelta hacia lo griego, entendido como el poder de lo inicial, cuya fuerza determinante se despliega aún en todos los principales hechos de la historia. Así como la nación alemana recuperará su potencialidad histórica por medio de la reafirmación de sus factores constitutivos biológicos y culturales (para ser justos, en Heidegger son estos últimos componentes los decisivos), de la misma manera la universidad alemana volverá a reconcentrarse en su esencia propia cuando la filosofía recupere su centralidad y el saber vuelva a reapropiarse de su verdadera esencia original. Esta esencia está claramente mostrada en la nueva (y en realidad, antigua) definición de la ciencia que Heidegger propone en su Discurso de rectorado y que corresponde claramente a su idea de la filosofía: "Ciencia: cuestionando, tenerse de pie en medio del ente en su totalidad, el cual está constantemente volviendo al ocultamiento" (SDU, p. 10).

Ahora bien, a pesar de esta inclinación favorable al nazismo, no puede afirmarse que la concepción heideggeriana de la ciencia (filosofía) expresada aquí, lo sea. Y tampoco otras ideas que aparecen en el mismo texto, como, por ejemplo, la que se expone en la frase escrita inmediatamente después de la definición citada. "Esta obstinación activa (la ciencia) sabe al mismo tiempo algo de su impotencia frente al destino". Esta afirmación reexpone algo que en algunos párrafos anteriores se había ya mostrado a través de una cita del Prometeo de Esquilo: "Pero el saber es mucho más débil que la necesidad". Heidegger explica esta frase de la siguiente manera: "Lo que quiere decir: todo saber sobre las cosas queda en primer lugar librado a la sobrepotencia del destino y fracasa frente a él'". Esta idea muestra el alcance profundo que tiene la idea de una reasunción del espíritu de la cultura griega, cuyos resultados no solamente tienen que ver con la forma del nuevo impulso que ha de darse a las ciencias y a la universidad, sino también con los límites que este impulso debe saber alcanzar. Y en esto también se hace patente el alcance que tiene la crítica de Heidegger a la modernidad: la modernidad pretende que el hombre a través del saber puede dirigir tanto su vida personal, como su vida social e histórica, lo cual mirado desde el espíritu griego constituye una Hybris. Esta limitación puesta por Heidegger muestra claramente la confusión que hay en su crítica, que por un lado lo empuja hacia la política y a tener cierta simpatía con el nazismo, pero por otro lo aleja de él, en cuanto el nazismo mismo también se presenta como un fenómeno doble: es crítico de la modernidad, como impulso político antidemocrático y antirrepublicano, pero también se presenta como una modernidad ultrancista, en cuanto pretende reorganizar completamente la vida de los alemanes, no solamente en el terreno sociopolítico, sino además en todos los aspectos de la vida. La gran empresa planificada de exterminación del pueblo judío y de los enemigos del régimen, los planes de colonización hacia los territorios del este, 
la movilización para consumar los planes bélicos, el control de la economía, de la educación, de la cultura, en breve, todos los aspectos centrales del régimen nazi, pueden ser perfectamente interpretados como una distorsión superlativa de la tecnificación y de la planificación y, por consiguiente, como una forma de expansión del aspecto más corrosivo de la modernidad. Si tomamos esto en consideración, la frase de Heidegger advirtiendo sobre los límites del saber podría servir de base a una crítica del nazismo y serán precisamente estas ideas las que comenzarán a mostrarse en el momento en que su camino tome otros rumbos. Lo determinante es que Heidegger acierta y se equivoca al mismo tiempo, y la causa de su equivocación es siempre su nacionalismo y su inmersión en razonamientos de tipo político. Su filosofía aparece "intervenida" por aspectos no filosóficos, lo que nos fuerza a separar en él la paja política del trigo filosófico, acción que tiene una justificación válida en la grandeza de lo que es verdadero pensamiento.

Por extraño que parezca, Heidegger cayó en la trampa de la Hybris que él mismo denunció, al sacar conclusiones sin asumir la finitud de su propio saber. Eligió no ver, porque, habiendo entrado en temas que requerían un saber completo, o por lo menos muy desarrollado, sobre ciertas cosas implicadas en esos asuntos tratados, se quedó enredado en prejuicios ajenos a su condición de filósofo. Por supuesto que esta prueba de ignorancia tiene que ver directamente con su nacionalismo, por el cual buscando un arraigo que le parecía necesario, se empecinó en él y se cerró a la universalidad. Convencido de que Alemania era el centro del mundo y la única legítima heredera de la sabiduría griega, se permitió afirmaciones que, más que otra cosa, ponen de manifiesto sus limitaciones humanas. En su ceguera y obcecación nacionalista, no se dio cuenta de que la herencia griega no solo se juega en el campo de la reflexión filosófica o en la palabra poética, sino en múltiples aspectos que llevan dentro de sí un pensamiento, aunque este no esté expuesto en una modalidad académica. El cine, la novela, la política, la plástica, los descubrimientos científicos y las proezas técnicas expanden a su manera la herencia griega, sin necesidad de dar respuestas directas sobre el ser o sobre la naturaleza del hombre y del mundo. En ellas, el pensamiento se ejerce de manera indirecta, hasta el punto de que sus logros pueden llegar a ser mucho más decisivos para la vida humana que los tratados de los filósofos. El mismo Heidegger afirma en alguna parte que Sófocles no necesitó escribir una ética para dar una respuesta profunda a los problemas de la acción humana. Lo mismo se podría afirmar sobre Faulkner o sobre Proust, por ejemplo, quienes no han necesitado escribir una psicología o un tratado de filosofía del lenguaje para desentrañar con agudeza inigualada los enigmas del alma humana o los misterios del habla.

Que Heidegger, debido a su nacionalismo, haya caído en desatinos tan grandes como los que podemos encontrar en algunas de sus obras cuando habla de otros pueblos, es algo que desorienta, pero al mismo tiempo señala con claridad los límites de 
su sabiduría y la magnitud de su ignorancia sobre otras realidades. Veamos algunos ejemplos de esto:

"Nosotros sabemos hoy día que el mundo anglosajón del americanismo está decidido a aniquilar Europa, es decir, la patria, es decir, el comienzo de Occidente. Lo inicial es indestructible (...). El espíritu oculto de lo inicial en Occidente ni siquiera tendrá una mirada de menosprecio por este proceso de auto-devastación de lo que no tiene comienzo; él alcanzará su hora sideral entregándose al reposo sereno de lo inicial" (Heidegger, HHI, p. 68).

Lo absurdo de esta frase es la atribución exclusiva de "lo inicial" (la herencia griega) a Alemania o, más precisamente, la exclusión de dicho inicio del mundo anglosajón, que no se sabe por qué estaría fuera de esta tradición de la cual sin embargo forma parte. Como si existiera la veta pura, que se prolongaría hacia Europa sin el mundo anglosajón representado por USA, y este último, que sería una derivación bastarda y sin posibilidades de prolongar dicho destino. Las razones de esta exclusión no se dan, simplemente se afirman, como si fuera obvio que la categoría de "anglosajón" o de "americanismo" quedara excluida de la tradición pura de Occidente. Habría que afirmar entonces que Walt Witman o Edgar Alan Poe, que Hemingway o Steinbeck, que Chaplin o John Ford, que Melville o Mark Twain, que Woody Allen o Stanley Kubrick, que Eduard Hoper o Jackson Pollock, pertenecen a esta avanzada demoníaca que amenaza Occidente. El síndrome de fortaleza amenazada, de peligro exterior, de horror frente a la otredad, característico de la Alemania nacionalsocialista, le obnubila completamente la mirada hasta el punto de ver solo lo que ven los ojos del miedo.

La misma absurda afirmación, ahora con connotaciones geopolíticas, encontramos en la Introducción a la metafísica:

"Esta Europa que en un enceguecimiento incurable se encuentra siempre a punto de apuñalarse a sí misma, está encerrada en una tenaza entre la Rusia de una parte y América de la otra. Rusia y América son ambas, desde un punto de vista metafísico, la misma cosa; el mismo frenesí siniestro de la técnica desencadenada y de la organización sin raíces del hombre normalizado" (Heidegger, EM, pp. 49-50).

La frase podría figurar en los anales de la ceguera que ella misma pretende denunciar, pues sería difícil encontrar un ejemplo más claro de "frenesí siniestro de la técnica desencadenada" que la propia Alemania de Hitler, en medio de la cual esta frase es pronunciada y para la cual Heidegger, enredado como está en su inexplicable nacionalismo, no tiene lucidez ninguna.

Pero también los logros políticos de una cultura tienen que ser considerados desde este punto de vista, si es que es verdad que el inicio tiene un poder determinante. El pensamiento no puede reducirse a la filosofía y a las artes, pues también se ejerce en la determinación de lo justo y lo injusto, o en las formas en que la tradición occidental configura a su modo particular, y de acuerdo a los principios que la conducen, una cierta forma de sociedad y de gobierno, o una cierta manera de constituirse 
los pueblos en naciones, y hasta una cierta manera de orientarse hacia perspectivas políticas que se van abriendo en el curso de la historia. Lo griego no solamente es decisivo como "ciencia", en el sentido restrictivo en que lo entiende Heidegger, sino también en cuanto derivación histórica llevada a cabo por los esfuerzos y las luchas de los hombres. Alejandro Magno, en cuanto ejecutor de una cierta forma de la universalidad, entendida como "helenidad", es tan importante para la determinación de lo occidental como el incuestionable aporte filosófico de su maestro Aristóteles. ¿Y podría encontrarse algo más determinantemente "griego" que la política que el Contrato Social ha intentado repensar? No hay en esto ningún tipo de precedencia, porque cada uno de estos aspectos reenvía hacia el otro y lo requiere para mostrar su efecto determinante.

Por eso, podría uno volver la argumentación de Heidegger en contra de él mismo, afirmando que mucho más ajeno al destino de Occidente es el nazismo, que las democracias, cuyo desarrollo histórico más coherente ha sido llevado a cabo precisamente por el "americanismo" anglosajón que él tanto parece despreciar. Felizmente, el destino de Occidente estaba lejos de transitar por las vías señaladas por Hitler y que tanto entusiasmaron al filósofo. Los logros de la democracia demostraron que daban lugar a una potencia cultural mucho más poderosa que la verborrea ideológica nazi de la que Heidegger no supo distanciarse, y si la historia ha seguido ese camino no ha sido solamente porque esta opción se haya impuesto por las armas. Su fuerza radica precisamente en que sus principios resultan de una coherencia mucho mayor con el resto de los factores determinantes de lo occidental. Así, es imprescindible volver a Heidegger contra sí mismo, para no arrojar a la basura lo valioso junto con lo desechable, y para recuperar lo que en su pensamiento va mas allá de los mezquinos partidismos.

Y si hubiera que encontrar uno de los puntos extremos en este lamentable desvarío nacionalista de Heidegger, habría que señalar su escandaloso olvido de la influencia de la Revolución Francesa y, en particular, de uno de sus más grandes inspiradores, el propio Rousseau, en la evolución política y filosófica de Alemania. Puede leerse a Rousseau como un crítico de la modernidad y en su nostalgia de una comunidad fraternal y de una vida sencilla y solidaria, podrían encontrarse también muchos puntos de confluencia con las reivindicaciones provincianas de Heidegger frente al avance desenfrenado de la técnica. Pero su nacionalismo fue superior a él, como lo demuestran los trabajos que él dedica al poeta que él consideraba, tal vez con justicia, como el anunciador de los tiempos venideros, Hölderlin, el "profeta de Occidente". El pensador de Friburgo pareciera haber intentado depurar su arte de las influencias revolucionarias, para hacerlo aparecer como el poeta puramente alemán que él hubiera deseado que fuera. Empresa inútil, pues las palabras finales del poema de Hölderlin dedicado a Rousseau hablan por sí solas:

...Y ¡ Oh milagro! como si él hubiera ya experimentado desde el comienzo

La esencia y todos los actos del espiritu humano,

la viejas maneras de la vida

Sabe él desde los primeros signos lo que habrá de cumplirse 


\section{Y vuela el audaz espiritu como el águila ante la tormenta}

Vaticinando sus dioses que ya llegan.

Después de la barbarie del siglo XX, en la que las bases filosóficas de la universalidad de lo humano parecen haberse derrumbado y en la que las ideas de libertad e igualdad parecieran haber perdido su vigencia, atender al mensaje de Hölderlin y volver a leer a Rousseau, para buscar en él el vaticinio de esos dioses que ya llegan y que tienen que ver directamente con eso que no vio Heidegger en su obcecación nacionalista, esto es, con el sentido universalista y la fuerza de lo común y lo recíproco, se presenta ahora como una tarea que parece ineludible. Con sus campos de concentración, el nazismo nos descubrió esa humanidad desnuda que el filósofo alemán no siempre supo ver, la misma que el ginebrino pareciera haber tenido constantemente ante sus ojos.

\section{Referencias bibliográficas}

Carrasco, Eduardo (2007), "Filosofía y política". Revista de Filosofía. 63: 9-35.

Heidegger, Martin (EM) (1952), Einfúhrung in die Metaphysik. Max Niemayer Verlag Tübingen.

Heidegger, Martin (HHI) (1989), Hölderlin Hymne "Der Ister" (Sommersemester 1942) Gesamtausgabe, t. 53 Frankfurt am Main: Klostermann.

Heidegger, Martin (LWS) (1998), Logik als die Frage nach dem Wesen der Sprache. Frankfurt am Main: Klostermann.

Heidegger, Martin (RL) (2000), Reden und Andere Zeugnisse eines Lebensweges 1910-1976. Frankfurt am Main: Klostermann.

Heidegger, Martin (SDU) (1933), Die Selbstbehauptung der deutschen Universität. Breslau: Verlag Wilh. Gottl. Korn.

Heidegger, Martin (SZ) (1976), Sein und Zeit. Tübingen: Niemeyer.

Hobbes, Thomas (L) (2003), Leviatán, Trad. Antonio Escohotado. Buenos Aires: Losada.

Littel, Jonathan (LB) (2006), Les Bienveillantes. Éditions Gallimard, Paris: Gallimard.

Nietzsche, Friedrich (WDB) (1955), Werke in drei Bände, Herausgegeben von Karl Schlechta. München: Carl Hanser Verlag.

Rousseau, Jean-Jacques (CS) (2001), Du Contrat Social, Paris: GF Flammarion. 